\title{
Leaching and in vitro bio-accessibility of aluminium from different teas
}

Tingting Lin and Xiaoping Yang*

Key Laboratory of Horticultural Plant Biology (Huazhong Agricultural University), Ministry of Education, Wuhan 430070, P.R. China

\begin{abstract}
To assess human exposure to aluminum ( $\mathrm{Al}$ ) from tea, the total $\mathrm{Al}$ contents in different teas (green tea, black tea and oolong tea processed with same fresh leaves) and the leaching of $\mathrm{Al}$ from these teas were analyzed, and the bio-accessibility of $\mathrm{Al}$ from these teas and their infusions was evaluated under simulated gastrointestinal condition. The results showed that green tea contained a high level of $\mathrm{Al}$, but the leaching rate of $\mathrm{Al}$ from it was low, and the brewing condition significantly affected the leaching rate. It was also found that the leaf age significantly affected the content of $\mathrm{Al}$ in tea, but no significant differences were observed in the $\mathrm{Al}$ content among different teas and in the $\mathrm{Al}$ leaching from these teas. Results also showed that the bio-accessibility of $\mathrm{Al}$ from green tea infusion was very low after simulated gastrointestinal digestion, and there were no significant differences in the bio-accessibility of $\mathrm{Al}$ from different tea infusions. It is concluded that drinking tea is relatively safe and it is no cause for concern about $\mathrm{Al}$ toxicity in healthy individuals.
\end{abstract}

\section{Introduction}

Aluminum ( $\mathrm{Al})$ is toxic to humans. It has been reported that a high level of brain Al damages not only nervous system but also cardiovascular system, hepatobiliary system, respiratory system, endocrine system, urinary system, and so on [1]. Epidemiological studies also showed that excessive $\mathrm{Al}$ in the body might lead to Alzheimer's disease (AD), osteomalacia, dialysis encephalopathy, microcytic anemia, and so on [2]. Therefore, a reduced intake of dietary $\mathrm{Al}$ is of crucial importance to prevent the toxicity of Al.

Tea is one of the most popular drinks around the world, and hundreds of millions of people drink tea daily for health benefits such as antioxidant activity, preventing cardiovascular disease, and weight management [3]. However, tea plant is an $\mathrm{Al}$ accumulator [4], and $\mathrm{Al}$ is mainly accumulated in leaves [5]. Therefore, tea drinking may be a potentially important source of dietary $\mathrm{Al}$, and more and more people have been becoming interested in whether drinking tea increases the risk of some diseases such as AD.

The intake of $\mathrm{Al}$ from tea drinking depends on the following aspects: total $\mathrm{Al}$ content in tea, $\mathrm{Al}$ leaching into tea infusion, and the bioavailability of $\mathrm{Al}$ from tea infusion in the body [6]. The total $\mathrm{Al}$ content in tea varies with many factors, such as soil characteristics [7], tea plant variety, especially leaf age [5]. It has been reported that old leaves contain average $5600 \mathrm{mg} \cdot \mathrm{kg}^{-1} \mathrm{Al}$ and young leaves average 997 mg.kg ${ }^{-1}$ [8]. The leaching of $\mathrm{Al}$ into tea infusion depends on the solubility of $\mathrm{Al}$ and brewing conditions besides the amount present in the tea. It has been reported that the solubility of $\mathrm{Al}$ is low for $\mathrm{Al}$ in tea is bound by polyphenols, fluoride, and so on [9-11]. The bioavailability of Al from tea infusion seemed also be low in the body. Powell et al. [12] reported that only a small proportion of $\mathrm{Al}$ in tea infusion was available for absorption in the gastrointestinal tract. Yokel and Florence [13] reported that oral Al bioavailability from tea infusion was only $0.37 \%$. From these findings, drinking tea might not contribute significantly to the total body burden of Al.

To accurately estimate the daily intake of $\mathrm{Al}$ from tea consumption and the risk of $\mathrm{Al}$, it is important to evaluate total $\mathrm{Al}$ content in tea, the leaching of $\mathrm{Al}$ from the tea, and the bio-accessibility of $\mathrm{Al}$ from its infusion after digestion at the same time. It is also necessary to compare the difference of total $\mathrm{Al}$ contents in green tea, black tea, and oolong tea, of the Al leaching from these teas, and of the bio-accessibility of $\mathrm{Al}$ from their infusions because green tea, black tea, and oolong tea were processed with different manufacturing processed, and different manufacturing processed might lead to the different effects on the total $\mathrm{Al}$ content in tea, thus affecting the leaching of $\mathrm{Al}$ from them and the bio-accessibility of $\mathrm{Al}$ from their infusion. The present study aims to determinate total $\mathrm{Al}$ contents in green tea, black tea, and oolong tea processed with same fresh leaves and the leaching of $\mathrm{Al}$ from these teas, and to evaluate the bio-accessibility of $\mathrm{Al}$ from their infusions under simulated gastrointestinal conditions.

\section{Materials and methods}

\section{Materials}

Porcine pepsin was purchased from Sigma-Aldrich Chemical Company (St. Louis, MO). Porcine pancreatin (CAS. 8049-47-6) and porcine stomach mucin were purchased from Shanghai Yuanye BioTechnology Co., Ltd (China). Porcine pancreatic lipase (CAS. 9001-621) was purchased from Shanghai Aladdin Industrial Inc. (China). All reagents and chemicals used were of analytical grade.

\section{Processing of tea}

Fresh tea leaves of Camellia sinensis L. were harvested from tea

Correspondence to: Xiaoping Yang, College of Horticulture and Forestry Sciences, Huazhong Agricultural University, Wuhan 430070, P.R. China, Tel: 862787286948; Fax: 862787282010; E-mail: yangxp@mail.hazu.edu.cn

Key words: tea, aluminium, bio-accessibility, leaching

Received: October 20, 2016; Accepted: November 07, 2016; Published: November 11, 2016 
plantation at Huazhong Agricultural University (HZAU), Wuhan, China. These leaves were respectively manufactured into green tea, black tea, and oolong tea at the tea processing factory on HZAU campus. The teas were ground, sieved through a 40 -mesh stainless steel sieve $(0.42 \mathrm{~mm})$, and stored at $-20^{\circ} \mathrm{C}$ for further use.

\section{Total Al content in tea}

$1.0 \mathrm{~g}$ of oven-dried tea sample was dry-ashed according to the method of Akinyele and Shokunbi [14]. Total Al content in the tea was analyzed by atomic absorption spectrometry (AAs) as described in Bertsch and Bloom [15].

\section{Leaching of Al from tea}

$2.0 \mathrm{~g}$ of milled green tea, black tea, and oolong tea was soaked in 100 $\mathrm{mL}$ deionized water at $90^{\circ} \mathrm{C}$ for 20 minutes, respectively. The mixtures were centrifuged at $4846 \times \mathrm{g}$ for $10 \mathrm{~min}$ to get tea infusions. $10 \mathrm{~mL}$ of tea infusion was transferred into porcelain crucibles. The porcelain crucibles were heat overnight to vaporize water according to the method of Moreno et al. [16]. The residues in porcelain crucibles were dry-ashed and analyzed for $\mathrm{Al}$ content as described above. The leaching rate of $\mathrm{Al}$ was calculated as the percentage between the amount of $\mathrm{Al}$ in tea infusion and in tea.

\section{Effect of brewing condition on Al leaching from tea}

Batch experiments, including tea to water ratio (tea/water), leaching temperature, leaching time and leaching times, were carried out by adding the above milled green tea into $250 \mathrm{~mL}$ glass conical flasks containing deionized water in thermostatic water bath for some time. Then, the mixtures were centrifuged at $4846 \times \mathrm{g}$ for $10 \mathrm{~min}$ and the supernatants were collected for the determination of $\mathrm{Al}$ content as described above. The effect of tea/water (1:20, 1:40, 1:60, 1:80, 1:100 and 1:150 g.mL $\left.{ }^{-1}\right)$ was conducted by adding the milled tea $(5.0,2.5$, $1.67,1.25,1.0$ and $0.67 \mathrm{~g}$ ) to $100 \mathrm{~mL}$ deionized water at $90^{\circ} \mathrm{C}$ for 20 minutes. The effect of leaching temperature was done by adding $2.0 \mathrm{~g}$ of the milled tea into $100 \mathrm{~mL}$ deionized water at different temperature $\left(60,70,80,90\right.$ and $\left.100^{\circ} \mathrm{C}\right)$ for 20 minutes. The effect of leaching time was conducted by adding $2.0 \mathrm{~g}$ of the milled tea into $100 \mathrm{~mL}$ deionized water at $90^{\circ} \mathrm{C}$ for different time $(3,5,10,20,40$ and $60 \mathrm{~min})$. The effect of leaching times was done according to the following description: $2.0 \mathrm{~g}$ of the milled tea was added to $100 \mathrm{~mL}$ deionized water at $90^{\circ} \mathrm{C}$ for 20 minutes, the mixture was centrifuged and the supernatant was collected as the first infusion; the same tea sample was used for making a second and then a third infusion, using $100 \mathrm{~mL}$ of deionized water at $90^{\circ} \mathrm{C}$ each time for 20 minutes, respectively.

\section{Determination of in vitro bio-accessibility of Al from tea infusion and tea}

The preparation of simulated gastric, duodenal, and bile juices and the in vitro gastrointestinal digestion of tea infusion were done according to the method of Flores et al. [17]. Briefly, simulated gastric juice was composed of $2.5 \mathrm{~g}$ pepsin, $3.0 \mathrm{~g}$ mucin, $2.752 \mathrm{~g} \mathrm{NaCl}, 0.824$ $\mathrm{g} \mathrm{KCl}, 0.266 \mathrm{~g} \mathrm{NaH}_{2} \mathrm{PO}_{4}, 0.399 \mathrm{~g} \mathrm{CaCl}_{2} .2 \mathrm{H}_{2} \mathrm{O}, 0.306 \mathrm{~g} \mathrm{NH}_{4} \mathrm{Cl}, 0.085$ g urea, $6.5 \mathrm{ml}$ concentrated $\mathrm{HCl}$ in $500 \mathrm{ml} \mathrm{H}_{2} \mathrm{O}$. Simulated duodenal juice was composed of $9.0 \mathrm{~g}$ pancreatin, $1.5 \mathrm{~g}$ lipase, $7.012 \mathrm{~g} \mathrm{NaCl}$, $0.564 \mathrm{~g} \mathrm{KCl}, 3.388 \mathrm{~g} \mathrm{NaHCO}_{3}, 80.0 \mathrm{mg} \mathrm{KH}_{2} \mathrm{PO}_{4}, 50.0 \mathrm{mg} \mathrm{MgCl}, 0.1 \mathrm{~g}$ urea, $0.180 \mathrm{ml}$ concentrated $\mathrm{HCl}$ in $500 \mathrm{ml} \mathrm{H}_{2} \mathrm{O}$. Simulated bile juice was composed of $30.0 \mathrm{~g}$ bile salts, $5.259 \mathrm{~g} \mathrm{NaCl}, 0.376 \mathrm{~g} \mathrm{KCl}, 5.785 \mathrm{~g}$ $\mathrm{NaHCO}_{3}, 0.25 \mathrm{~g}$ urea, $0.150 \mathrm{ml}$ concentrated $\mathrm{HCl}$ in $500 \mathrm{ml} \mathrm{H}_{2} \mathrm{O}$. The $\mathrm{pH}$ of the simulated gastric, duodenal and bile juices was adjusted to $1.30 \pm$ $0.02,8.1 \pm 0.2,8.2 \pm 0.2$, respectively with $1 \mathrm{M} \mathrm{HCl}$ or $1 \mathrm{M} \mathrm{NaOH}$.
$10 \mathrm{~mL}$ of tea infusion ( $3.0 \mathrm{~g}$ of milled teas was extracted with 100 $\mathrm{mL}$ deionized water at $90^{\circ} \mathrm{C}$ for $10 \mathrm{~min}$.) was digested sequentially as follows: stomach - addition of $12 \mathrm{~mL}$ of gastric juice and mixing for $2 \mathrm{~h}$; and intestine-addition of $12 \mathrm{~mL}$ of duodenal and $6 \mathrm{~mL}$ of bile juices and mixing for $2 \mathrm{~h}$. Aliquots were collected at $0.5 \mathrm{~h}$ intervals for a total of $4 \mathrm{~h}$, and centrifuged at $4846 \times \mathrm{g}$ for $10 \mathrm{~min}$. The supernatants were stored at $-20^{\circ} \mathrm{C}$ prior to further analyses for $\mathrm{Al}$ content. The amount of $\mathrm{Al}$ in the supernatant was considered bioaccessible and available for the absorption into the systematic circulation from the gut. The bioaccessibility of $\mathrm{Al}$ was calculated as the percentage between the concentration after digestion and before digestion. The in vitro bioaccessibility of $\mathrm{Al}$ from teas was calculated after $0.5 \mathrm{~g}$ of milled tea was digested as described above.

\section{Statistical analysis}

All data were expressed as the mean \pm SD of three replications of the experiment. Statistical analysis was performed by one-way analysis of variance followed by LSD test. Significant difference was considered at $\mathrm{p}<0.05$.

\section{Results}

\section{Total Al contents in tea}

The total Al contents in green tea with different leaf ages are shown in Table 1 . We found that the content significantly increased with the age of leaf, and it in four leaves and a bud green tea was 6.9 times as high as that in a bud green tea. The total Al contents in black tea and oolong tea showed similar changing trends to that in green tea with the increase of leaf age (data not shown). This was in agreement with the report of Xie et al. [7], who showed that the content of $\mathrm{Al}$ in old leaves was 1.1- 3.3 times higher than that in mature leaves and 5.2-17.8 times higher than that in young leaves. Hence, consumers can reduce $\mathrm{Al}$ intake through drinking tea processed with young leaves.

The total $\mathrm{Al}$ contents in different types of teas processed with same fresh leaves (bud with two leaves) are shown in Table 2. No significant differences were observed in the total $\mathrm{Al}$ contents of green tea, black tea, and oolong tea. This was not in agreement with several previous reports that tea types significantly affected total $\mathrm{Al}$ contents in teas. For example, Zhou et al. [18] found that $\mathrm{Al}$ contents in teas were oolong tea $\left(1943\right.$ mg. $\left.\mathrm{kg}^{-1}\right)>$ black tea $\left(1565 \mathrm{mg} \cdot \mathrm{kg}^{-1}\right)>$ green tea $\left(699 \mathrm{mg} . \mathrm{kg}^{-1}\right)$, and Wong et al. [8] also reported that $\mathrm{Al}$ contents were oolong tea $\left(1010 \mathrm{mg} \cdot \mathrm{kg}^{-1}\right)>$ black tea $\left(782 \mathrm{mg} \cdot \mathrm{kg}^{-1}\right)>$ green tea $\left(675 \mathrm{mg} \cdot \mathrm{kg}^{-1}\right)$. The disagreement might be mainly attributed to different fresh leaves for processing teas. The teas in the study of Zhou et al. [18] were purchased

Table 1. The content and leaching of Al from green tea ${ }^{[\mathrm{a}]}$

\begin{tabular}{|c|c|c|c|}
\hline Tender & Total Al (mg.kg-1) & Leached Al (mg.L $\left.L^{-1}\right)$ & Leaching rate $(\%)$ \\
\hline Bud & $250.51 \pm 22.67^{\mathrm{e}}$ & $1.42 \pm 0.14^{\mathrm{e}}$ & $29.25 \pm 0.39^{\mathrm{b}}$ \\
\hline Bud with a leaf & $646.21 \pm 23.04^{\mathrm{d}}$ & $3.57 \pm 0.17^{\mathrm{d}}$ & $28.91 \pm 1.36^{\mathrm{b}}$ \\
\hline Bud with two leaves & $1137.09 \pm 17.59^{c}$ & $6.40 \pm 0.11^{\mathrm{c}}$ & $29.41 \pm 0.51^{\mathrm{ab}}$ \\
\hline Bud with three leaves & $1434.06 \pm 26.91^{b}$ & $8.42 \pm 0.18^{b}$ & $30.67 \pm 0.64^{\mathrm{a}}$ \\
\hline Bud with four leaves & $1717.33 \pm 33.41^{\mathrm{a}}$ & $9.39 \pm 0.17^{\mathrm{a}}$ & $29.13 \pm 0.57^{b}$ \\
\hline
\end{tabular}

${ }^{\mathrm{a}}$ Means followed by different letters in the same column indicate significant differences at $\mathrm{p}<0.05$ according to LSD test.

Table 2. The content and leaching of Al from different types of teas (bud with two leaves).

\begin{tabular}{|l|c|c|c|}
\hline Type of tea & Total Al $\left(\mathbf{m g . k g}^{-1}\right)$ & Leached Al $\left(\mathbf{m g . L} \mathbf{L}^{-1}\right)$ & Leaching rate (\%) \\
\hline Green tea & $1183.31 \pm 23.61$ & $6.79 \pm 0.22$ & $30.44 \pm 0.96$ \\
\hline Black tea & $1148.60 \pm 29.44$ & $7.04 \pm 0.11$ & $30.65 \pm 0.50$ \\
\hline Oolong tea & $1203.15 \pm 31.62$ & $6.97 \pm 0.03$ & $30.19 \pm 0.14$ \\
\hline
\end{tabular}


from supermarket, and the teas in the study of Wong et al. [8] were processed with fresh leaves from different plantations. It was difficult to ensure that the quality of fresh leaves was same, thus affecting the total $\mathrm{Al}$ contents in teas processed with these fresh leaves, for the total $\mathrm{Al}$ contents in fresh leaves were affected by soil characteristics, plant variety, especially leaf age. It was noted that green tea was generally made from young and tender leaves, and black tea, especially oolong tea, were made from more mature leaves than green tea. Wong et al. [8] had also showed that the green tea was processed with buds and two leaves while old leaves were used for black tea and oolong tea in their study. Therefore, they showed that tea types significantly affected total $\mathrm{Al}$ contents in teas. In our study, green tea, black tea and oolong tea were processed with same fresh leaves through different manufacturing processes, and the effect of tea types on the $\mathrm{Al}$ content was only from different manufacturing processes. We did not observe significant differences in total $\mathrm{Al}$ contents of these teas, which suggested that different manufacturing processes did not significantly affect the $\mathrm{Al}$ contents in teas and the $\mathrm{Al}$ contents in teas might be mainly related to the quality of fresh leaves, especially leave ages.

\section{Leaching of Al from tea}

As shown in Tables 1 and 2, the leaching of $\mathrm{Al}$ from green tea, black tea and oolong tea was low, and the leaching rate was only about $30 \%$, although the total contents in them were considerably high. This was

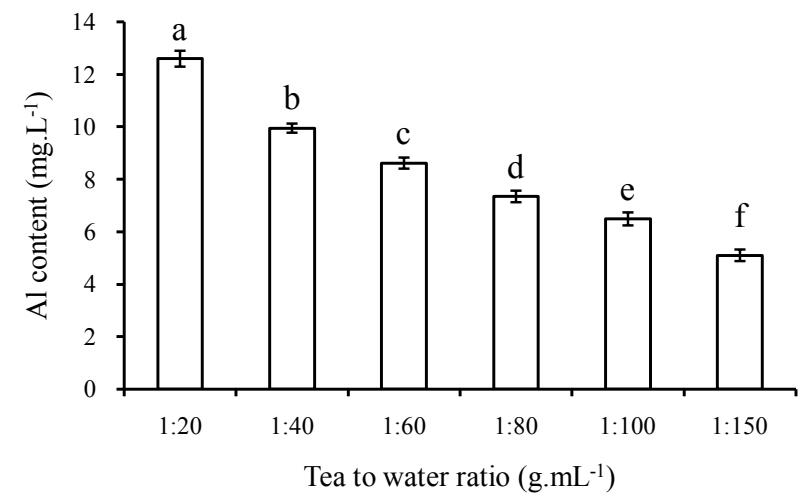

A

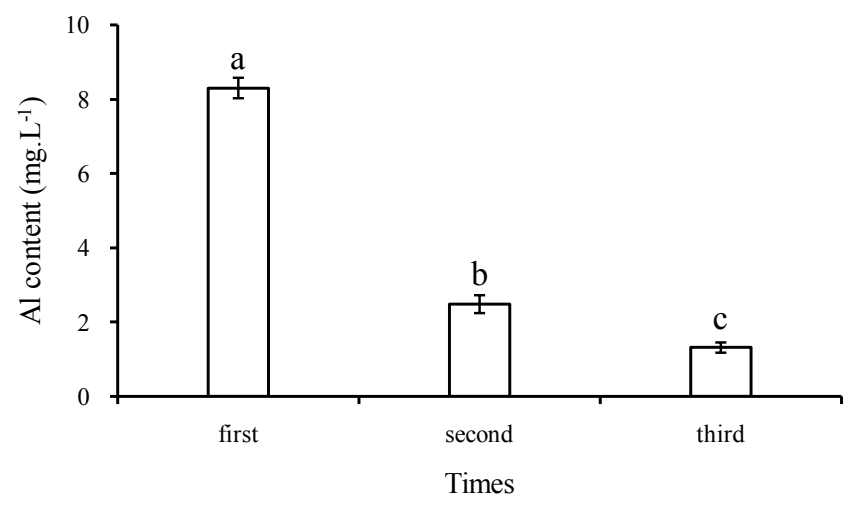

C consistent with the report of Wróbel et al. [19], who showed that the leaching rate of $\mathrm{Al}$ from green tea was $28.7 \%$, and of Moghaddam et al. [20], who showed that the leaching rates from different teas were from 23.9\%-34.6\%. The low leaching rate might be due to that $\mathrm{Al}$ in teas was bound by organic compounds such as polyphenols [10,11], and it also formed complexes with fluoride (F) [9], which hindered the leaching of $\mathrm{Al}$ from teas. No significant differences were observed in the leaching of $\mathrm{Al}$ from green tea, black tea and oolong tea.

With the increase of leaf age, the total $\mathrm{Al}$ content in green tea increased significantly, the leached $\mathrm{Al}$ in its infusion also increased significantly (Table 1 ). However, the leaching rate of $\mathrm{Al}$ did not show the similar trend. The leaching rate from four leaves and a bud green tea was significantly lower than that from three leaves and a bud green tea. This might be due to that the F content in tea also increased with leaf age, and $\mathrm{Al}$ formed more complexes with $\mathrm{F}$ in old leave [5,21], thus decreasing the leaching rate. The leaching of $\mathrm{Al}$ from black tea and oolong tea also showed a similar trend to that of green tea with the increase of leaf age.

\section{Effect of brewing condition on Al leaching from tea}

The leaching of $\mathrm{Al}$ into tea infusion depends on not only the $\mathrm{Al}$ amount present in the tea, its solubility but also the brewing condition. As shown in Figure 1, tea/water, brewing temperature, times and time significantly affected the leaching of $\mathrm{Al}$ from green tea. The $\mathrm{Al}$ content in

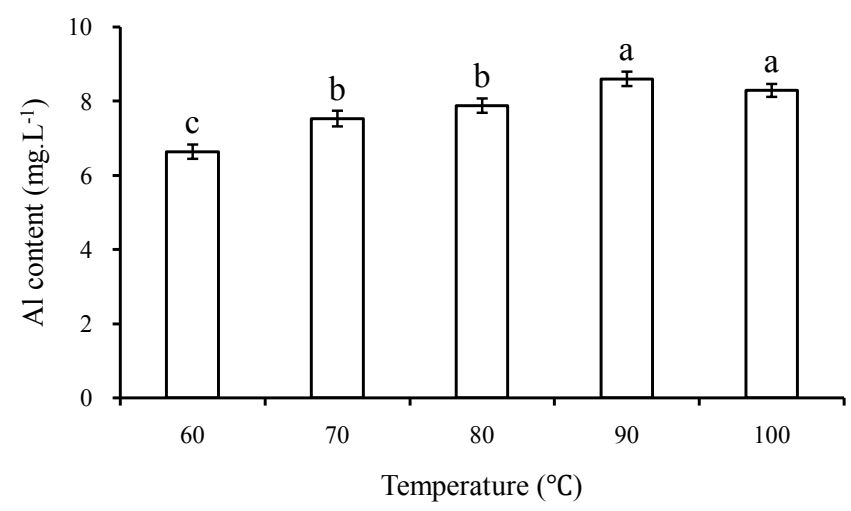

B

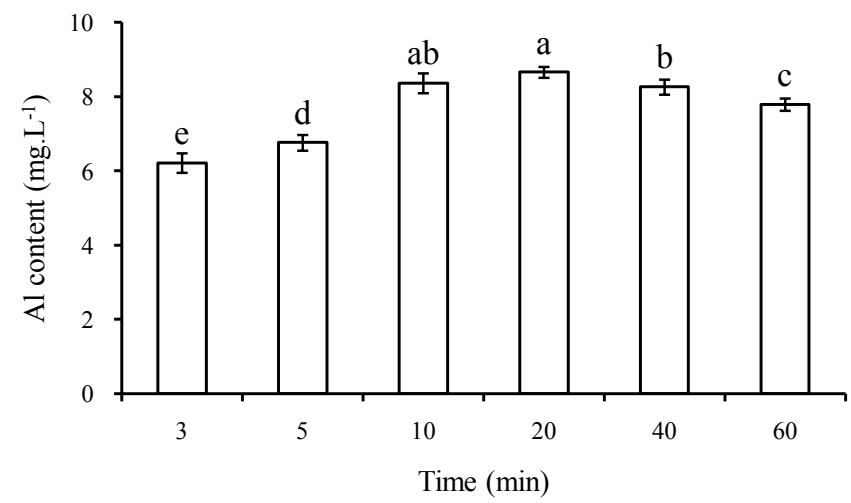

$\mathrm{D}$

Figure 1. Effect of tea to water ratio (A), temperature (B), times (C), and time (D) on Al leaching from tea [The milled green tea was added into $250 \mathrm{~mL}$ glass conical flasks containing 100 $\mathrm{mL}$ deionized water in thermostatic water bath for some time. Then, the mixtures were centrifuged at $4846 \times \mathrm{g}$ for 10 min and the supernatants were collected for the determination of $\mathrm{Al}$ content. Means followed by different letters indicate significant differences at $\mathrm{p}<0.05$ according to LSD test]. 
tea infusion decreased significantly with the decrease of tea/water, and increased significantly with the increase of brewing temperature when the brewing temperature was not higher than $90^{\circ} \mathrm{C}$. It decreased when the brewing temperature was over $90^{\circ} \mathrm{C}$, but no significant difference was observed between $90^{\circ} \mathrm{C}$ and $100^{\circ} \mathrm{C}$. We also observed that the $\mathrm{Al}$ content in the first infusion was significantly higher than that in the second infusion, and $68.6 \%$ of soluble $\mathrm{Al}$ was leached into the first infusion. It in the second infusion was significantly higher than that in the third infusion, and $20.5 \%$ of soluble $\mathrm{Al}$ was leached into the second infusion. A similar finding has been reported by Mehra and Baker [22]. Finally, the Al content in tea infusion significantly increased with increasing infusion time in the first $10 \mathrm{~min}$ of infusing, and significantly decreased after 20 min of infusing. The effect of brewing condition on $\mathrm{Al}$ leaching from black tea and oolong tea showed a similar trend to that of green tea. These suggest that it is conductive to reduce $\mathrm{Al}$ intake through increasing water consumption, decreasing water temperature and brewing time when making tea.

\section{In vitro bio-accessibility of $\mathrm{Al}$ from tea infusion and tea}

Table 3 shows the bio-accessibility of $\mathrm{Al}$ from the infusions of green tea, black tea and oolong tea after simulated gastrointestinal digestion. The results revealed that the bio-accessibility of $\mathrm{Al}$ from tea infusions was very high and over $94 \%$ after $2 \mathrm{~h}$ of gastric digestion, while it was very low and only about $5.1 \%$ after another $2 \mathrm{~h}$ of duodenal digestion. Similarly, the bio-accessibility of $\mathrm{Al}$ from teas was relatively high and about $47 \%$ after $2 \mathrm{~h}$ of gastric digestion, while it was very low and only about $5.5 \%$ after another $2 \mathrm{~h}$ of duodenal digestion (Table 4 ). These showed that the bio-accessibility of $\mathrm{Al}$ from both teas and their infusions was very low in the intestine, which was in agreement with several previous studies. Although teas contained high concentrations of $\mathrm{Al}$, only a small proportion was available for absorption in the gastrointestinal tract [12]. Mehra and Baker [22] also reported that the availability of $\mathrm{Al}$ from teas was only $4.96 \%$ for absorption in the intestine. The poor bio-accessibility of $\mathrm{Al}$ might be due to its poor solubility in the intestine. It has been reported that $\mathrm{Al}$ was relatively insoluble at $\mathrm{pH} 6.0-8.0$ [23]. These suggested that tea consumption impossibly provided an appreciable proportion of the daily dietary intake of $\mathrm{Al}$ because $\mathrm{Al}$ absorption mainly occurred in the intestine

Table 3. The bio-accessibility (\%) of $\mathrm{Al}$ from tea infusions after in vitro gastrointestinal digestion $^{[\mathrm{a}]}$.

\begin{tabular}{|l|l|l|l|l|l|}
\hline Time (h) & Type of tea & $\mathbf{0 . 5}$ & $\mathbf{1 . 0}$ & $\mathbf{1 . 5}$ & $\mathbf{2 . 0}$ \\
\hline Gastric digestion & Green tea & $74.72 \pm 3.01^{\text {cde }}$ & $91.23 \pm 1.89^{\text {bd }}$ & $97.00 \pm 1.81^{\mathrm{a}}$ & $97.84 \pm 2.07^{\mathrm{a}}$ \\
\cline { 2 - 6 } & Black tea & $71.45 \pm 3.09^{\text {ce }}$ & $88.11 \pm 2.72^{\text {bde }}$ & $94.02 \pm 1.99^{\mathrm{a}}$ & $94.93 \pm 1.63^{\mathrm{a}}$ \\
\cline { 2 - 6 } & Oolong tea & $76.91 \pm 1.58^{\text {cd }}$ & $86.51 \pm 2.38^{\text {be }}$ & $94.94 \pm 2.03^{\mathrm{a}}$ & $96.41 \pm 2.22^{\mathrm{a}}$ \\
\hline \multirow{2}{*}{$\begin{array}{l}\text { Duodenal } \\
\text { digestion }\end{array}$} & Green tea & $4.73 \pm 0.95$ & $5.31 \pm 0.99$ & $5.19 \pm 0.92$ & $5.13 \pm 0.87$ \\
\cline { 2 - 6 } & Black tea & $4.91 \pm 0.83$ & $5.75 \pm 0.97$ & $5.26 \pm 0.84$ & $5.08 \pm 0.96$ \\
\cline { 2 - 6 } & Oolong tea & $4.82 \pm 0.97$ & $5.84 \pm 0.83$ & $5.52 \pm 0.79$ & $5.43 \pm 1.01$ \\
\hline
\end{tabular}

${ }^{\mathrm{a}}$ Means followed by different letters in the same row $(\mathrm{a}, \mathrm{b}, \mathrm{c})$ and in the same column of gastric digestion $(\mathrm{d}, \mathrm{e})$ indicate significant differences at $\mathrm{p}<0.05$ according to LSD test.

Table 4. The bio-accessibility (\%) of $\mathrm{Al}$ from teas after in vitro gastrointestinal digestion ${ }^{[a]}$.

\begin{tabular}{|l|l|l|l|l|l|}
\hline Time (h) & Type of tea & $\mathbf{0 . 5}$ & $\mathbf{1 . 0}$ & $\mathbf{1 . 5}$ & $\mathbf{2 . 0}$ \\
\hline Gastric digestion & Green tea & $28.28 \pm 0.86^{\mathrm{cde}}$ & $35.33 \pm 0.93^{\mathrm{b}}$ & $46.12 \pm 1.09^{\mathrm{a}}$ & $46.78 \pm 0.99^{\mathrm{a}}$ \\
\cline { 2 - 6 } & Black tea & $29.81 \pm 0.53^{\mathrm{cd}}$ & $36.67 \pm 1.30^{\mathrm{b}}$ & $46.13 \pm 0.64^{\mathrm{a}}$ & $46.93 \pm 1.28^{\mathrm{a}}$ \\
\cline { 2 - 6 } & Oolong tea & $27.85 \pm 0.96^{\mathrm{ce}}$ & $36.12 \pm 0.76^{\mathrm{b}}$ & $46.49 \pm 1.05^{\mathrm{a}}$ & $47.13 \pm 1.12^{\mathrm{a}}$ \\
\hline \multirow{3}{*}{$\begin{array}{l}\text { Duodenal } \\
\text { digestion }\end{array}$} & Green tea & $5.85 \pm 0.93^{\mathrm{c}}$ & $11.88 \pm 1.29^{\mathrm{a}}$ & $8.03 \pm 1.15^{\mathrm{b}}$ & $5.46 \pm 1.05^{\mathrm{c}}$ \\
\hline & Black tea & $4.32 \pm 0.75^{\mathrm{c}}$ & $12.28 \pm 1.10^{\mathrm{a}}$ & $6.32 \pm 1.13^{\mathrm{b}}$ & $5.52 \pm 1.20^{\mathrm{bc}}$ \\
\cline { 2 - 6 } & Oolong tea & $4.23 \pm 1.01^{\mathrm{c}}$ & $10.30 \pm 1.20^{\mathrm{a}}$ & $6.45 \pm 1.01^{\mathrm{b}}$ & $5.72 \pm 0.92^{\mathrm{bc}}$ \\
\hline
\end{tabular}

${ }^{a}$ Means followed by different letters in the same row $(a, b, c)$ and in the same column of gastric digestion $(\mathrm{d}, \mathrm{e})$ indicate significant differences at $\mathrm{p}<0.05$ according to LSD test.
[24]. The bio-accessibility of $\mathrm{Al}$ from teas was significantly lower than that from their infusions after $2 \mathrm{~h}$ of gastric digestion, which might be due to the action of polyphenols in teas, which avidly bound trivalent metals $\left(\mathrm{Al}^{3+}\right)[12]$, and of $\mathrm{F}$ in them, which formed complexes with $\mathrm{Al}$ [9].

We observed that digestion time affected the bio-accessibility of $\mathrm{Al}$ from the teas and their infusions under simulated gastrointestinal conditions. The bio-accessibilities of $\mathrm{Al}$ from both teas and their infusions significantly increased with the prolonged gastric digestion time and reached equilibrium after $1.5 \mathrm{~h}$ of digestion. However, Al bioaccessibilities from teas first increased significantly with the prolonged intestinal digestion time, and then significantly decreased after $1.0 \mathrm{~h}$ of digestion. Al bio-accessibilities from tea infusions showed a similar trend of change with the prolonged intestinal digestion time, but no significant differences were observed.

In the comparison of the bio-accessibilities of $\mathrm{Al}$ from green tea, black tea and oolong tea after simulated gastrointestinal digestion, no significant differences were observed between them except that the bio-accessibility from black tea was significantly higher than that from oolong tea at $0.5 \mathrm{~h}$ of gastric digestion. There were also no significant differences between the bio-accessibility of $\mathrm{Al}$ from different tea infusions after simulated gastrointestinal digestion, except that the bioaccessibility from oolong tea infusion was significantly higher than that from black tea infusion at $0.5 \mathrm{~h}$ of gastric digestion, and it from green tea infusion was significantly higher than that from oolong tea infusion at $1.0 \mathrm{~h}$ of gastric digestion. These were similar to the report of Fujii et al. [25], who showed that there were no significant differences in the availability of $\mathrm{Al}$ from green tea infusion, black tea infusion and oolong tea infusion in the gastrointestinal tract.

We assume that an adult drinks $10 \mathrm{~g}$ of tea daily, then $5.1 \mathrm{mg}$ of $\mathrm{Al}$ can be ingested from drinking tea infusion according to $1700 \mathrm{mg} . \mathrm{kg}^{-1}$ of average total $\mathrm{Al}$ content and $30 \%$ of leaching rate, and about 0.28 $\mathrm{mg}$ of $\mathrm{Al}$ (5.5\% of the bio-accessibility) is accessible in the intestine. Then, the maximum amount of daily $\mathrm{Al}$ intake from tea into the body should be $0.28 \mathrm{mg}$ because $\mathrm{Al}$ may not be completely absorbed in the intestines [26], and daily consumption of tea is often less than $10 \mathrm{~g}$. The amount is markedly below the standard of the United Nations food and agriculture organization/the world health organization (FAO/WHO) that the acceptable daily intake (ADI) of $\mathrm{Al}$ is $1.0 \mathrm{mg} \cdot \mathrm{kg}^{-1}$ body weight/ day [27]. The evidences suggest that tea consumption impossibly contributes an appreciable daily dietary intake of $\mathrm{Al}$, thus leading to markedly negative health effect. Contrarily, it has potentially positive effect on human health for its rich antioxidant polyphenols [28].

In general, green tea, black tea, and oolong tea contained high contents of $\mathrm{Al}$, and the total $\mathrm{Al}$ contents in them significantly increased with the leaf age. However, the leaching of $\mathrm{Al}$ into tea infusions was low, and brewing condition significantly affected the leaching. Moreover, the bio-accessibility of $\mathrm{Al}$ from the teas and their infusions were very low after simulated gastrointestinal digestion. No significant differences were observed in the total $\mathrm{Al}$ contents in green tea, black tea, and oolong tea processed with same fresh leaves, and there were also no significant differences in the leaching of Al from these teas, and in the bio-accessibility of $\mathrm{Al}$ from these teas and their infusions after simulated gastrointestinal digestion. From our findings, we suggest that drinking tea is no cause for concern about $\mathrm{Al}$ toxicity in healthy individuals.

\section{Acknowledgments}

This work was financially supported by the Fundamental Research 
Funds for the Central Universities, China (grant no. 2013PY091).

\section{References}

1. Nayak P (2002) Aluminum: impacts and disease. Environ Res 89: 101-115.[crossref]

2. Soni MG, White SM, Flamm WG, Burdock GA (2001) Safety evaluation of dietary aluminum. Regul Toxicol Pharmacol 33: 66-79.[crossref]

3. Pinto MS (2013) Tea: A new perspective on health benefits. Food Res Int 53: 558-567.

4. Fung KF, Zhang ZQ, Wong JW, Wong MH (2003) Aluminium and fluoride concentrations of three tea varieties growing at Lantau Island, Hong Kong. Environ Geochem Health 25: 219-232. [crossref]

5. Shu WS, Zhang ZQ, Lan CY, Wong MH (2003) Fluoride and aluminium concentrations of tea plants and tea products from Sichuan Province, PR China. Chemosphere 52: 1475-1482.[crossref]

6. Karak T, Bhagat RM (2010) Trace elements in tea leaves, made tea and tea infusion: A review. Food Res Int 43: 2234-2252.

7. Xie ZL, Dong DM, Bao GZ, Wang ST, Du YG et al. (2001) Aluminum content of tea leaves and factors affecting the uptake of aluminum from soil into tea leaves. Chinese Geogr Sci 11: 87-91.

8. Wong MH, Zhang ZQ, Wong JWC, Lan CY (1998) Trace metal contents (Al, Cu and $\mathrm{Zn}$ ) of tea: tea and soil from two tea plantations, and tea products from different provinces of China. Environ Geochem Health 20: 87-94.

9. Nagata T, Hayatsu M, Kosuge N (1993) Aluminum kinetics in the tea plant using $27 \mathrm{Al}$ and 19 F NMR. Phytochemistry 32: 771-775.

10. Flaten AK, Lund W (1997) Speciation of aluminium in tea infusions studied by size exclusion chromatography with detection by post-column reaction. Sci Total Environ 207: 21-28.[crossref]

11. Tang DS, Shen SR, Chen X, Zhang YY, Xu CY (2004) Interaction of catechins with aluminum in vitro. $J$ Zhejiang Univ Sci 5: 668-675.[crossref]

12. Powell JJ, Greenfield SM, Parkes HG, Nicholson JK, Thompson RP (1993) Gastrointestinal availability of aluminium from tea. Food Chem Toxicol 31: 449-454.[crossref]

13. Yokel RA, Florence RL (2008) Aluminum bioavailability from tea infusion. Food Chem Toxicol 46: 3659-3663. [crossref]

14. Akinyele IO, Shokunbi OS (2015) Comparative analysis of dry ashing and wet digestion methods for the determination of trace and heavy metals in food samples. Food Chem 173: 682-684.[crossref]

15. Bertsch PM, Bloom PR (1996) Aluminum, in Methods of Soil Analysis, Part 3, Chemical Methods, ed. by Sparks DL, Page AL, Helmke PA, Loeppert RH, Soltanpour
PN, Tabatabai MA, et al. Soil Science Society of America, Inc., Madison, Wisconsin, pp.517-550.

16. Moreno IM, González-Weller D, Gutierrez V, Marino M, Cameán AM, et al. (2008) Determination of $\mathrm{Al}, \mathrm{Ba}, \mathrm{Ca}, \mathrm{Cu}, \mathrm{Fe}, \mathrm{K}, \mathrm{Mg}, \mathrm{Mn}, \mathrm{Na}, \mathrm{Sr}$ and $\mathrm{Zn}$ in red wine samples by inductively coupled plasma optical emission spectroscopy: Evaluation of preliminary sample treatments. Microchem J 88: 56-61.

17. Flores FP, Singh RK, Kerr WL, Pegg RB, Kong FB (2014) Total phenolics content and antioxidant capacities of microencapsulated blueberry anthocyanins during in vitro digestion. Food Chem 153: 272-278.

18. Zhou CY, Wu J, Chi H, Wong MK, Koh LL, et al. (1996) The behaviour of leached aluminium in tea infusions. Sci Total Environ 177: 9-16.

19. Wróbel K, Wróbel K, Urbina EMC (2000) Determination of total aluminum, chromium, copper, iron, manganese, and nickel and their fractions leached to the infusions of blacktea, green tea, hibiscus sabdariffa, and ilex paraguariensis (Mate) by ETA-AAS Biol Trace Elem Res 78: 271-280.

20. Moghaddam MA, Mahvi AH, Asgari AR, Yonesian M, JahedGh, et al. (2008) Determination of aluminum and zinc in Iranian consumed tea. Environ Monit Assess 144: 23-30.[crossref]

21. Xie ZL, Chen Z, Sun WT, Guo XJ, Yin B, et al. (2007) Distribution of aluminum and fluoride in tea plant and soil of tea garden in Central and Southwest China. Chinese Geogr Sci 17, 376-382.

22. Mehra A, Baker CL (2007) Leaching and bioavailability of aluminium, copper and manganese from tea (Camellia sinensis). Food Chem 100: 1456-1463.

23. Driscoll CT, Postek KM (1996) The chemistry of aluminum in surface waters, in The Environmental Chemistry of Aluminum (2nd ed.), ed. by Sposito G. Lewis Publishers, New York, pp. 363-418.

24. Berthon G (2002) Aluminum speciation in relation to aluminum bioavailability, metabolism and toxicity. Coord Chem Rev 228: 319-341.

25. Fujii W, Kusumoto A, Nakada T, Suwa Y (2002) Gastrointestinal absorption of aluminum from teas in rats. J Food Sci 67: 2552-2554.

26. Ganrot PO (1986) Metabolism and possible health effects of aluminium. Environ Health Perspect 65: 363-441.[crossref]

27. JECFA (Joint FAO/WHO Expert Committee on Food Additives) (1999) Summary of evaluations performed by the Joint FAO/WHO expert committee on food additives, JECFA 1956-2003. ILSI Press, International Life Sciences Institute, Washington, DC, USA.

28. Pẹkal A, Dróżdż P, Biesaga M, Pyrzynska K (2012) Screening of the antioxidant properties and polyphenol composition of aromatised green tea infusions. $J$ Sci Food Agric 92: 2244-2249. [crossref]

Copyright: (C2016 Lin T. This is an open-access article distributed under the terms of the Creative Commons Attribution License, which permits unrestricted use, distribution, and reproduction in any medium, provided the original author and source are credited. 